\title{
Clinical Indicators and Thresholds for Determining Discharge Destination from Acute Stroke Ward
}

\author{
Kazuaki Iokawa, OTR, $\mathrm{PhD}^{1}$, Toshimasa Sone, OTR, $\mathrm{PhD}^{2}$, \\ Takaaki Fujita, OTR, PhD², Tetsu Tsukada, OTR, $\mathrm{PhD}^{3}$, \\ Mariko Kaneda, OTR ${ }^{3}$, Keiichi Hasegawa, OTR, MS $^{3}$ \\ ${ }^{1}$ Preparing section for New Faculty of Medical Science, Fukushima Medical University, Fukushima, Japan \\ ${ }^{2}$ Department of Rehabilitation, Faculty of Health Science, Tohoku Fukushi University, Sendai, Japan \\ ${ }^{3}$ Department of Rehabilitation, Takeda General Hospital, Aizuwakamatsu, Japan
}

\begin{abstract}
Objective: The present study aimed to investigate the complex interaction of factors affecting discharge destination after the acute phase of stroke.

Methods: In 304 patients with stroke who required rehabilitation, we focused on three discharge destinations (i.e., home, convalescent rehabilitation ward, and other facility). Sociodemographic, medical, and acute symptoms data, within the first week of stroke onset and discharge destination, were collected from acute stroke wards. The complex interaction of factors relating to discharge destination from an acute stroke ward was investigated by classification and regression tree analysis.

Results: Patients with a total Functional Independence Measure (FIM) score $>35$, a Brunnstrom recovery stage of the lower limb $>V$, and a comprehension FIM score $>5$ had a 91.7\% chance of home discharge. By contrast, patients with a total FIM score $\leq 35$, age $\leq 79.5$ years, and $>2.5$ family members had an $80 \%$ chance of discharge to a convalescent rehabilitation ward. Finally, patients with a total FIM score $\leq 35$, age $>79.5$ years, and an expression FIM score $\leq 3$ had a $78.6 \%$ chance of discharge to other facilities.

Conclusion: The interaction of independence on FIM, function of the paralyzed lower limb, age, number of family members, and comprehension or expression function affect the choice of discharge destination from acute stroke wards.
\end{abstract}

Keywords: rehabilitation, stroke, prediction, discharge destination, classification and regression tree

(Asian J Occup Ther 15: 27-35, 2019)

\section{Introduction}

Discharge planning is important for patients after acute stroke to ensure that medical resources are used effectively through appropriate rehabilitation planning $[1,2]$. Acute care hospitals typically determine discharge destinations on the basis of a patient's initial status at hospitalization, with home, convalescent rehabilitation ward, other hospital, or long-term care facility being

Received: 10 April 2018, Accepted: 24 February 2019

Corresponding to: Kazuaki Iokawa, Preparing section for New Faculty of Medical Science, Fukushima Medical University, 1 Hikarigaoka, Fukushima City, Fukushima, 960-1295, Japan

e-mail: iokawa@fmu.ac.jp

C2019 Japanese Association of Occupational Therapists the main options. Prediction of discharge destination at an early stage is necessary for implementing effective occupational therapy for patients with acute stroke. A previous study has reported that improved prediction of discharge destination could shorten acute stays, improve outcomes, and reduce treatment costs [3]. Therefore, a patient's discharge destination should be considered soon after admission $[2,4]$.

The rehabilitation team plays a key role in evaluating activity limitations and rehabilitation tolerance, and they are therefore important for determining discharge destinations [5]. Especially, occupational therapists are required to be involved in determining discharge destinations in the rehabilitation team because they are responsible for supporting patients' activities and social participation. In general, stroke rehabilitation in Japan 
is delivered in acute, convalescent, and maintenance phases [6]. During the acute phase in acute care settings, rehabilitation aims to encourage compensatory functions in the cerebrum to restore the functional impairment while preventing disuse syndromes [6]. Once this phase has passed, patients enter the convalescent phase. If further improvement of function can be expected, these patients undergo intensive rehabilitation in convalescent rehabilitation wards until they are discharged from hospital [6]. The main purpose of rehabilitation in the maintenance phase is to maintain the acquired functions, activities, and social participation for as long as possible. In the maintenance phase, patients use home-visit rehabilitation or facility services, such as the welfare facilities for the elderly requiring long-term care, in long-term care insurance system. However, patients are often discharged to their homes after using the rehabilitation of facility service in the health care facilities for the elderly requiring long-term care.

Discharge destination after acute stroke has been reported to be predicted by many factors, including age, race, gender, medical complications/comorbidities, neurological complications, and environmental and socioeconomic factors [4]. In particular, younger age has been identified as a significant factor for being discharged home [7-9]. High scores on Functional Independence Measures (FIM) of activities of daily living (ADL) at admission have also been associated with home discharge versus discharge to other settings [10]. Indeed, functional dependence of ADL on admission is considered the most important determinant of discharge destination by some researchers $[7,11,12]$, though the number of family members and the marital status have also been associated with better chances of being discharged home [11, 13]. Thus, the choice of discharge destination is influenced, not by a single factor, but by a combination of factors [2], that has yet to be clarified. This is further confounded by the fact that many previous studies on discharge destination after acute strokes have used dichotomous categories (i.e., home versus other facilities) [2, 9, 13-15], limiting their usefulness. That is, the dichotomous categories of discharge destination can predict patients who are likely to be discharged home, but cannot predict patients who are likely to be transferred to convalescent rehabilitation ward.

In Japan, there is a need to develop appropriate decision-making policies for discharge planning to convalescent rehabilitation wards, other hospitals, or longterm care facilities. Moreover, this needs to be applicable in the acute phase of stroke. Therefore, we aimed to investigate the complex interaction of factors that influence discharge destination after acute stroke, focusing specifically on discharge to home, convalescent rehabilitation wards, or other facilities. Furthermore, we aimed to analyze the combinations of related factors of discharge destination in clinically useful method (decision tree analysis). This information could be used by not only professionals in acute stroke ward, such as medical doctor, occupational therapists and physical therapists, but also patients and family members to facilitate discharge planning as early as possible during hospitalization. Furthermore, by being able to predict discharge destination, the problems of ADL of patients and the needs of patients and their families will become concrete, and the goal of occupational therapy can be set more clearly. In other words, the prediction of discharge destination enables more effective occupational therapy program and environment adjustment (including welfare equipment) of the living situation in the acute phase of stroke. Moreover, by the early decision of the discharge destination, collaboration between acute care ward and post-discharge institution becomes possible from the early stage; therefore, occupational therapists can adjust necessary service contents and support system for patients, and seamlessly provide necessary occupational therapy to patients after discharge.

\section{Materials and Methods}

We enrolled patients admitted to the Takeda General Hospital with a diagnosis of stroke who were prescribed rehabilitation therapy between July 2014 and June 2016. For inclusion, patients were required to be aged $\geq 20$ years and to have their initial rehabilitation assessment conducted within 1 week of symptom onset. We excluded patients who died or had missing data. All enrolled patients were required to provide written consent for participation and were given an opportunity to refuse to participate in the study.

Takeda General Hospital is a certified Aizu Community-Based Rehabilitation Center in the Fukushima prefecture that has 897 hospital beds and offers multidisciplinary care for cerebrovascular disease [16]. The rehabilitation team consisted of a neurologist, a rehabilitation physician, an occupational therapist, a physiotherapist, a speech therapist, a nurse, and a social worker. Multidisciplinary team meetings were conducted weekly to discuss rehabilitation and discharge planning (including destination). During these meetings, the occupational therapists were asked by the doctors about the ADL goal based on functional prognosis. Furthermore, based on the results of the initial evaluation and the needs of patients and their families, occupational therapists were asked for opinions on the place of transference and the required services when performing patient's acute postrehabilitation. Based on the information collected at 
these meetings, the support staff creates a patient's discharge plan.

This study protocol was reviewed and approved by the Ethics Committee of Tohoku Fukushi University (RS14071106).

Occupational therapists collected all sociodemographic and medical data, such as age, sex, number of family members, dominant hand, type of stroke, affected side, and the history of illness. Furthermore, occupational therapists assessed the acute symptoms of stroke patients within the first week of symptom onset, as follows: consciousness [Japan Coma Scale (JCS) score] [17], upper limb function [Brunnstrom recovery stage (BRS) for the upper limb] [18], lower limb function (BRS for the lower limb) [18], sensation in the upper and lower limbs, upper and lower limb joint range of motion, limb and trunk ataxia, agnosia, apraxia, aphasia, hemianopia, trunk control test [19], Functional Ambulation Categories classification [20], cognitive function [Hasegawa Dementia Scale-Revised (HDS-R) score] [21], and ADL (using the FIM) [22]. Moreover, evaluation in case of severe consciousness disorder was objectively evaluated based on the fact that it was confirmed by each test of the acute symptoms in principle. However, in particular, those with a consciousness level of 100-300 in JCS were rated as 0 in HDS-R. BRS was evaluated based on reactions that could be confirmed by palpation and observation scenes, and the sensation was mainly evaluated through a response by pain stimulus. Finally, we identified the discharge destination from the acute care ward.

\section{Statistical analysis}

Subjects were divided into three groups based on discharge destination (i.e., home, convalescent rehabilitation ward, or other facilities). Differences in sociodemographic profiles, medical profiles, and acute symptoms were tested among these groups by one-way analysis of variance for continuous variables or by the Kruskal-Wallis and chi-squared test for categorical variables. All statistical analyses were performed using the IBM SPSS Version 25.0 (IBM Corp., Armonk, NY, USA). The level of statistical significance was set at a $p$-value of $<0.05$. Descriptive data are presented as numbers (percentages) or as means \pm standard deviations (SDs).

Classification and regression tree (CART) analysis was used to investigate the complex interaction of factors related to discharge destination in the previous analyses. Binary trees were used to split predictor variables recursively with yes/no questions about each variable [23]. The CART algorithm produced a tree from the root by selecting the best predictor variable, defined as that with the lowest Gini index value as an internal node [24]. We specified a growing depth of three with the parent node having at least 10 subjects and a child node having at least three subjects [25]. The partitioning process was recursively applied until the stopping criteria were fulfilled or splitting was impossible [24]. Additionally, we performed a 10 -fold cross-validation in which we randomly divided data into 10 groups (nine used to build and one used to validate the model) [26]. The sample size of this study was based on the previous study that used a CART analysis [27] because it is difficult to determine the number of samples required for a study on the interaction of factors affecting discharge destination after the acute phase of stroke using CART analysis.

\section{Results}

In total, 414 patients were enrolled during the study period, from which we excluded 110 patients (12 died and 98 had missing data). Consequently, our final analysis included 304 patients. The mean time to assessment from symptom onset was $1.4 \pm 1.2$ days. The mean age was $78.5 \pm 11.7$ years, and the male to female distribution was similar (154 men and 150 women). Approximately $75 \%$ of patients had suffered cerebral infarctions. Histories of stroke and hypertension were present in $36.2 \%$ and $62.8 \%$, respectively, and approximately $60 \%$ of patients had a history of circulatory disease. The mean HDS-R score was $12.8 \pm 11.4$, and the mean FIM score was $44.0 \pm 25.2$. The clinical characteristics of the patients are summarized by discharge destination in Table 1.

Among the 304 patients, $102(33.6 \%)$ were discharged home, $107(35.2 \%)$ were transferred to a convalescent rehabilitation ward, and 95 (31.3\%) were transferred to other facilities. Concerning the sociodemographic and medical profiles, there were significant differences in the age, sex, number of family numbers, and history of mental and behavioral disorders among groups based on discharge destination. There were also significant differences in all acute symptoms except for trunk ataxia, apraxia, and hemianopia. Finally, significant differences were present for all FIM scores, except for stair climbing (Table 2).

In the CART analysis, the total FIM score ( $>35$ or $\leq 35)$ was identified as the single best discriminator of discharge destination (Fig. 1). Patients with a total FIM score $>35$, a BRS of the lower limb $>\mathrm{V}$, and an FIM comprehension score $>5$ had a $91.7 \%$ probability of home discharge. Moreover, patients with a total FIM score $>35$, a BRS of the lower limb $\leq \mathrm{V}$, and an FIM motor score $>44$ had an $81.2 \%$ probability of home 
Table 1. Characteristics of the study subjects $(n=304)$

\begin{tabular}{|c|c|c|c|c|}
\hline \multirow[b]{2}{*}{ Variables } & \multicolumn{3}{|c|}{ Discharge destination from acute care ward } & \multirow[b]{2}{*}{$P$ value } \\
\hline & $\begin{array}{c}\text { Home } \\
(\mathrm{n}=102)\end{array}$ & $\begin{array}{c}\text { Convalescent } \\
\text { rehabilitation ward } \\
(\mathrm{n}=107)\end{array}$ & $\begin{array}{l}\text { Other facilities } \\
\quad(\mathrm{n}=95)\end{array}$ & \\
\hline Age, years, mean $\pm \mathrm{SD}$ & $75.4 \pm 12.1$ & $75.3 \pm 10.7$ & $85.6 \pm 9.3$ & $<.001$ \\
\hline Female, $\mathrm{n}(\%)$ & $47(46.1)$ & $46(43.0)$ & $57(60.0)$ & .039 \\
\hline Number of family members, mean $\pm \mathrm{SD}$ & $3.2 \pm 1.8$ & $2.8 \pm 1.7$ & $2.4 \pm 1.8$ & .007 \\
\hline Dominant hand side (right), $\mathrm{n}(\%)$ & $102(100)$ & $105(98.1)$ & $94(98.9)$ & .392 \\
\hline Type of stroke (ischemic/ hemorrhage), n (\%) & $84(82.4) / 18(17.6)$ & $74(69.2) / 33(30.8)$ & $69(72.6) / 26(27.4)$ & .165 \\
\hline Paralyzed side (right), $\mathrm{n}(\%)$ & $45(44.1)$ & $59(55.1)$ & $58(61.1)$ & .052 \\
\hline \multicolumn{5}{|l|}{ History of illness, $n(\%)$} \\
\hline Stroke & $34(33.3)$ & $39(36.4)$ & $37(38.9)$ & .713 \\
\hline Hypertension & $62(60.8)$ & $67(62.6)$ & $62(65.3)$ & .808 \\
\hline Heart disease & $29(28.4)$ & $32(29.9)$ & $33(34.7)$ & .608 \\
\hline Hyperlipidemia & $15(14.7)$ & $21(19.6)$ & $13(13.7)$ & .463 \\
\hline Diabetes mellitus & $24(23.5)$ & $32(29.9)$ & $17(17.9)$ & .135 \\
\hline \multicolumn{5}{|l|}{ Japan Coma Scale, n (\%) } \\
\hline Grade 0 , Normal & $59(57.8)$ & $26(24.3)$ & $6(6.3)$ & $<.001$ \\
\hline Grade 1 , Single digit & $37(36.3)$ & $61(57.0)$ & $47(49.5)$ & \\
\hline Grade 2, Double digits & $6(5.9)$ & $17(15.9)$ & $30(31.6)$ & \\
\hline Grade 3, Triple digits & $0(0)$ & $3(2.8)$ & $12(12.6)$ & \\
\hline \multicolumn{5}{|l|}{ BRS of the upper limb, n (\%) } \\
\hline I & $2(2.0)$ & $6(5.6)$ & $16(16.8)$ & $<.001$ \\
\hline II & $4(3.9)$ & $28(26.2)$ & $28(29.5)$ & \\
\hline III & $6(5.9)$ & $18(16.8)$ & $15(15.8)$ & \\
\hline IV & $11(10.8)$ & $20(18.7)$ & $16(16.8)$ & \\
\hline V & $26(25.5)$ & $22(20.6)$ & $12(12.6)$ & \\
\hline VI & $53(52.0)$ & $13(12.1)$ & $8(8.4)$ & \\
\hline \multicolumn{5}{|l|}{ BRS of the lower limb, $\mathrm{n}(\%)$} \\
\hline I & $3(2.9)$ & $4(3.7)$ & $13(13.7)$ & $<.001$ \\
\hline II & $3(2.9)$ & $22(20.6)$ & $25(26.3)$ & \\
\hline III & $5(4.9)$ & $13(12.1)$ & $14(14.7)$ & \\
\hline IV & $5(4.9)$ & $24(22.4)$ & $19(20.0)$ & \\
\hline V & $32(31.4)$ & $33(30.8)$ & $16(16.8)$ & \\
\hline VI & $54(52.9)$ & $11(10.3)$ & $8(8.4)$ & \\
\hline \multicolumn{5}{|l|}{ Sensation of the upper limb, $\mathrm{n}(\%)$} \\
\hline Deficit & $36(35.3)$ & $54(50.5)$ & $55(57.9)$ & .006 \\
\hline \multicolumn{5}{|l|}{ Sensation of the lower limb, $\mathrm{n}(\%)$} \\
\hline Deficit & $30(29.4)$ & $53(49.5)$ & $53(55.8)$ & $<.001$ \\
\hline \multicolumn{5}{|l|}{ ROM of the upper limb, $n(\%)$} \\
\hline Deficit & $6(5.9)$ & $11(10.3)$ & $21(22.1)$ & .002 \\
\hline \multicolumn{5}{|l|}{ ROM of the lower limb, n (\%) } \\
\hline Deficit & $7(6.9)$ & $9(8.4)$ & $18(18.9)$ & .014 \\
\hline \multicolumn{5}{|l|}{ Ataxia of limbs, $n(\%)$} \\
\hline Presence & $5(4.9)$ & $14(13.1)$ & $3(3.2)$ & .013 \\
\hline \multicolumn{5}{|l|}{ Ataxia of trunk, n (\%) } \\
\hline Presence & $2(2.0)$ & $7(6.5)$ & $1(1.1)$ & .060 \\
\hline \multicolumn{5}{|l|}{ Agnosia, n (\%) } \\
\hline Presence & $4(3.9)$ & $15(14.0)$ & $16(16.8)$ & .011 \\
\hline \multicolumn{5}{|l|}{ Apraxia, n (\%) } \\
\hline Presence & $2(2.0)$ & $6(5.6)$ & $4(4.2)$ & .395 \\
\hline \multicolumn{5}{|l|}{ Aphasia, n (\%) } \\
\hline Presence & $11(10.8)$ & $25(23.4)$ & $31(32.6)$ & .001 \\
\hline \multicolumn{5}{|l|}{ Hemianopia, n (\%) } \\
\hline Presence & $9(8.8)$ & $7(6.5)$ & $11(11.6)$ & .454 \\
\hline Trunk control test, mean \pm SD & $69.2 \pm 37.0$ & $33.4 \pm 37.9$ & $12.7 \pm 26.2$ & $<.001$ \\
\hline Functional Ambulation Categories, mean $\pm \mathrm{SD} /$ median (range) & $1.6 \pm 1.6 / 2.0(0-3)$ & $0.3 \pm 0.8 / 0.0(0-0)$ & $0.2 \pm 0.6 / 0.0(0-0)$ & $<.001$ \\
\hline $\mathrm{HDS}-\mathrm{R}$ scores, mean $\pm \mathrm{SD}$ & $19.3 \pm 9.9$ & $14.3 \pm 10.8$ & $4.2 \pm 7.5$ & $<.001$ \\
\hline
\end{tabular}

BRS: Brunnstrom recovery stage; ROM: Range of motion; HDS-R: Hasegawa Dementia Scale-Revised; SD: standard deviation. 
Table 2. The Functional Independence Measure scores by discharge destination

\begin{tabular}{|c|c|c|c|c|}
\hline \multirow[b]{2}{*}{ Variables } & \multicolumn{3}{|c|}{ Discharge destination from acute care ward } & \multirow[b]{2}{*}{$P$ value } \\
\hline & $\begin{array}{c}\text { Home } \\
(\mathrm{n}=102)\end{array}$ & $\begin{array}{c}\text { Convalescent } \\
\text { rehabilitation ward } \\
(\mathrm{n}=107)\end{array}$ & $\begin{array}{l}\text { Other facilities } \\
\quad(\mathrm{n}=95)\end{array}$ & \\
\hline Eating, mean $\pm \mathrm{SD} /$ median (range) & $4.3 \pm 2.2 / 5(1-6)$ & $2.6 \pm 2.0 / 1(1-5)$ & $1.5 \pm 1.4 / 1(1-1)$ & $<.001$ \\
\hline Grooming, mean $\pm \mathrm{SD} /$ median (range) & $3.1 \pm 2.1 / 3(1-5)$ & $1.5 \pm 1.2 / 1(1-1)$ & $1.2 \pm 0.8 / 1(1-1)$ & $<.001$ \\
\hline Bathing, mean $\pm \mathrm{SD} /$ median (range) & $2.2 \pm 1.7 / 1(1-4)$ & $1.2 \pm 0.6 / 1(1-1)$ & $1.1 \pm 0.5 / 1(1-1)$ & $<.001$ \\
\hline Dressing upper body, mean $\pm \mathrm{SD} /$ median (range) & $2.3 \pm 1.5 / 1(1-4)$ & $1.4 \pm 0.8 / 1(1-1)$ & $1.1 \pm 0.5 / 1(1-1)$ & $<.001$ \\
\hline Dressing lower body, mean $\pm \mathrm{SD} /$ median (range) & $2.5 \pm 1.8 / 1(1-4)$ & $1.4 \pm 0.9 / 1(1-1)$ & $1.1 \pm 0.5 / 1(1-1)$ & $<.001$ \\
\hline Toileting, mean $\pm \mathrm{SD} /$ median (range) & $3.3 \pm 2.3 / 4(1-5)$ & $1.6 \pm 1.3 / 1(1-1)$ & $1.2 \pm 0.8 / 1(1-1)$ & $<.001$ \\
\hline Bladder management, mean $\pm \mathrm{SD} /$ median (range) & $3.9 \pm 2.8 / 3.5(1-7)$ & $1.9 \pm 1.7 / 1(1-2)$ & $1.2 \pm 1.1 / 1(1-1)$ & $<.001$ \\
\hline Bowel management, mean $\pm \mathrm{SD} /$ median (range) & $3.9 \pm 2.8 / 4(1-7)$ & $2.1 \pm 2.0 / 1(1-2)$ & $1.2 \pm 1.1 / 1(1-1)$ & $<.001$ \\
\hline Transfers to bed/chair/wheelchair, mean $\pm \mathrm{SD} /$ median (range) & $3.4 \pm 2.1 / 4(1-5)$ & $1.7 \pm 1.3 / 1(1-2)$ & $1.2 \pm 0.8 / 1(1-1)$ & $<.001$ \\
\hline Transfers to toilet, mean $\pm \mathrm{SD} /$ median (range) & $3.4 \pm 2.1 / 4(1-5)$ & $1.7 \pm 1.3 / 1(1-1)$ & $1.2 \pm 0.9 / 1(1-1)$ & $<.001$ \\
\hline Transfer to tub/shower, mean $\pm \mathrm{SD} /$ median (range) & $1.2 \pm 0.9 / 1(1-1)$ & $1.0 \pm 0.3 / 1(1-1)$ & $1.0 \pm 0.0 / 1(1-1)$ & .029 \\
\hline Walking or wheelchair propulsion, mean $\pm \mathrm{SD} /$ median (range) & $2.1 \pm 1.7 / 1(1-4)$ & $1.1 \pm 0.6 / 1(1-1)$ & $1.1 \pm 0.6 / 1(1-1)$ & $<.001$ \\
\hline Stair climbing, mean $\pm \mathrm{SD} /$ median (range) & $1.0 \pm 0.1 / 1(1-1)$ & $1.0 \pm 0.0 / 1(1-1)$ & $1.0 \pm 0.0 / 1(1-1)$ & .372 \\
\hline Comprehension, mean $\pm \mathrm{SD}$ /median (range) & $5.6 \pm 1.8 / 7(5-7)$ & $4.7 \pm 2.0 / 5(3-6)$ & $2.5 \pm 1.7 / 2(1-4)$ & $<.001$ \\
\hline Expression, mean $\pm \mathrm{SD} /$ median (range) & $5.7 \pm 1.8 / 6(5-7)$ & $4.5 \pm 2.1 / 5(3-6)$ & $2.4 \pm 1.8 / 2(1-3)$ & $<.001$ \\
\hline Social interaction, mean $\pm \mathrm{SD} /$ median (range) & $5.7 \pm 2.2 / 7(6-7)$ & $4.9 \pm 2.6 / 6(1-7)$ & $2.6 \pm 2.5 / 1(1-5)$ & $<.001$ \\
\hline Problem solving, mean $\pm \mathrm{SD} /$ median (range) & $4.7 \pm 2.6 / 6(1-7)$ & $3.3 \pm 2.5 / 1(1-5)$ & $1.7 \pm 1.6 / 1(1-1)$ & $<.001$ \\
\hline Memory, mean $\pm \mathrm{SD} /$ median (range) & $5.0 \pm 2.2 / 6(3-7)$ & $4.0 \pm 2.2 / 3(2-6)$ & $1.9 \pm 1.6 / 1(1-2)$ & $<.001$ \\
\hline Motor FIM Score, mean $\pm \mathrm{SD} /$ median (range) & $\begin{array}{c}36.7 \pm 19.9 / 36.5 \\
(16-56)\end{array}$ & $\begin{array}{l}20.1 \pm 10.9 / 14 \\
\quad(13-24)\end{array}$ & $\begin{array}{c}15.0 \pm 7.9 / 13 \\
(13-13)\end{array}$ & $<.001$ \\
\hline Cognitive FIM score, mean $\pm \mathrm{SD} /$ median (range) & $\begin{array}{c}26.7 \pm 9.7 / 32 \\
(18.8-35.0)\end{array}$ & $\begin{array}{c}21.3 \pm 9.6 / 22 \\
(14-30)\end{array}$ & $\begin{array}{c}11.0 \pm 7.7 / 8 \\
(5-14)\end{array}$ & $<.001$ \\
\hline Total FIM score, mean $\pm \mathrm{SD}$ /median (range) & $\begin{array}{c}63.4 \pm 27.3 / 64.5 \\
(38.8-89.0)\end{array}$ & $\begin{array}{c}41.3 \pm 17.1 / 39 \\
(27-51)\end{array}$ & $\begin{array}{c}26.1 \pm 13.3 / 21 \\
(18-27)\end{array}$ & $<.001$ \\
\hline
\end{tabular}

FIM: Functional Independence Measure; SD: standard deviation.

discharge, whereas those with a total FIM score $\leq 35$, age $\leq 79.5$ years, and with $>2.5$ family members had an $80 \%$ probability of discharge to a convalescent rehabilitation ward. Finally, patients with a total FIM score $\leq 35$, age $>79.5$ years, and FIM expression score $\leq 3$ had a $78.6 \%$ probability of discharge to other facilities (e.g., long-term care). The 10 -fold cross-validation showed that the outcomes of $61.5 \%$ of the patients were correctly predicted by the CART analysis.

\section{Discussion}

CART analysis indicated that functional ADL status, lower limb function, and comprehension ability at admission were most strongly associated with home discharge. Of note, the total FIM score at admission $(>35$ or $\leq 35)$ was the best predictor of discharge destination. A total FIM score of 35 points is almost at the level of total or maximal ADL assistance, indicating that complete dependence of ADLs (i.e., a total FIM score $\leq 35$ ) at the initial assessment within 1 week of stroke onset made home discharge very unlikely. By contrast, when patients with a total FIM score $>35$ had retained lower limb function (BRS of the lower limbs $>V$ ) and comprehension (FIM comprehension score $>5$ ), home discharge was more likely. Therefore, we recommend that occupational therapists use these results as clinical indicators and thresholds for determining discharge destination.

A BRS of the lower limb of VI implies normal muscle tone and control [28], and an FIM comprehension score $>5$ implies independence level [29]. After a stroke, patients are usually forced to rest in bed for medical treatment despite having functional ability. However, under conditions where ADLs were restricted, home discharge was the most likely, in our cohort, in case of BRS of the lower limbs > V and FIM comprehension score $>5$. Home discharge was also highly probable if patients with a total FIM score $>35$ and a BRS of the lower limb $\leq \mathrm{V}$ (i.e., apparent motor paralysis) had an FIM motor score $>44$. Despite the poor BRS, patients with an FIM motor score $>44$ can be expected to have relatively mild motor paralysis of the lower limbs because the average FIM motor score was $36.7 \pm 19.9$ in the home discharge group.

When the FIM motor score reaches the 40-point 


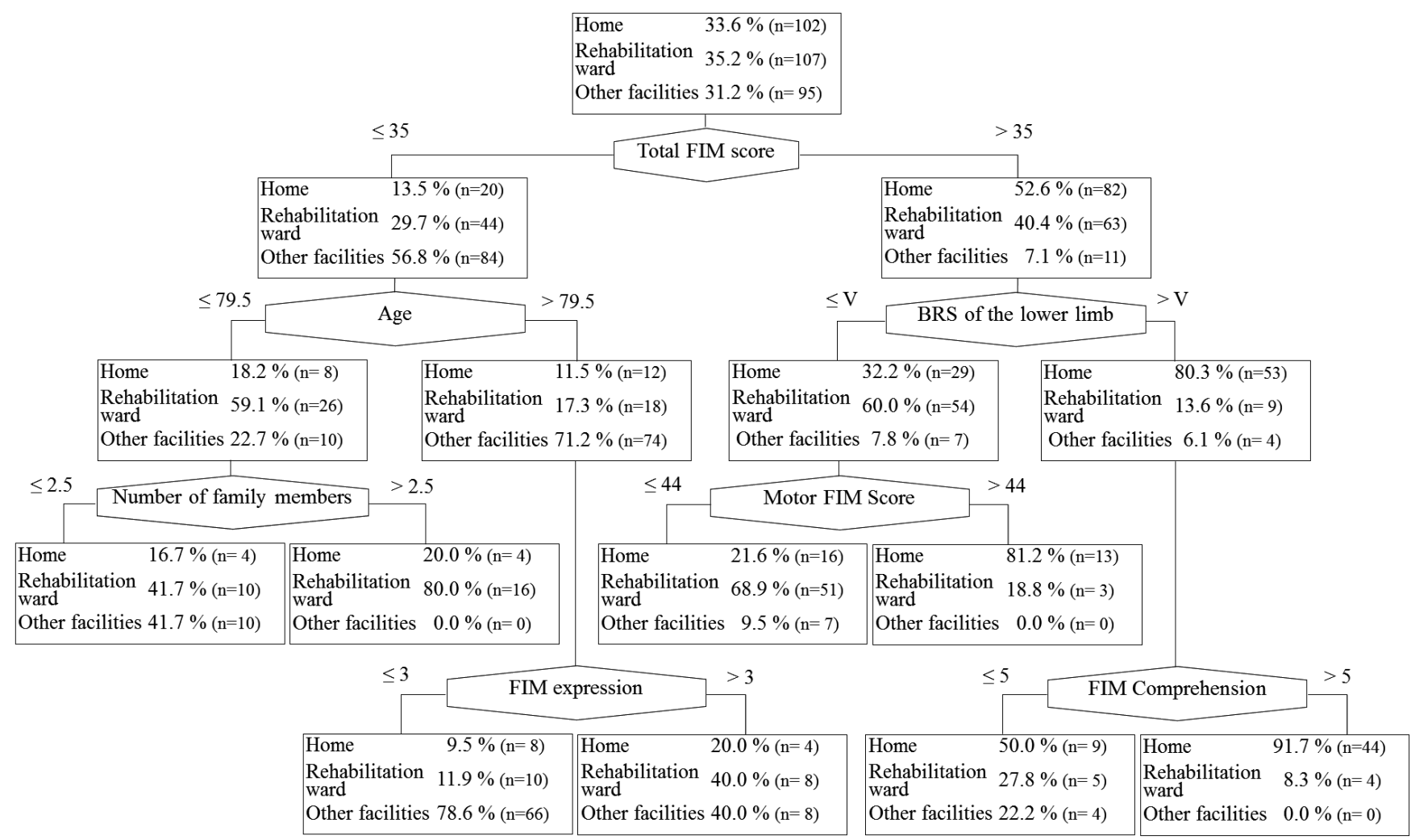

BRS: Brunnstrom recovery stage; FIM: Functional Independence Measure; Rehabilitation ward: Convalescent rehabilitation ward.

Fig. 1. Classification and regression tree for discharge destination after the acute phase of stroke

Patients with a total FIM score $>35$, a BRS of the lower limb $>$ V, and an FIM comprehension score $>5$ had a $91.7 \%$ probability of home discharge. Patients with a total FIM score $>35$, a BRS of the lower limb $\leq$ V, and an FIM motor score $>44$ had an $81.2 \%$ probability of home discharge, whereas those with a total FIM score $\leq 35$, age $\leq 79.5$ years, and with $>2.5$ family members had an $80 \%$ probability of discharge to a convalescent rehabilitation ward. Patients with a total FIM score $\leq 35$, age $>79.5$ years, and FIM expression score $\leq 3$ had a $78.6 \%$ probability of discharge to other facilities (e.g., long-term care).

level, it has been reported that other items of the motor FIM indicate less than moderate assistance, except for items related to bathing (bathing and transfer to tub/ shower) and locomotion (walk or wheelchair) [30]. Eating, bladder management, and bowel management are considered the easiest of the FIM motor items, whereas walking or wheelchair use, tub/shower transfer, using stairs, and bathing are the most difficult [31]. The results of the present study are consistent with these studies $[30,31]$. On the other hand, bathing-related activity and locomotion are highly likely to reduce the amount of assistance needed through welfare equipment and social resources [30]. Therefore, patients with 40 or more FIM motor points are likely to be discharged home [30]. Occupational therapists should conduct a detailed assessment of each activity of ADL, and it is important to carry out environmental interventions using assistive devices or welfare equipment from the acute stage. Additionally, if necessary, various services and social resources should be utilized.

When patients had a total FIM score $\leq 35$, were aged $\leq 79.5$ years, and had $>2.5$ family members, the chance of discharge to a convalescent rehabilitation ward increased. This suggested that, even if the ADL at stroke onset indicated the need for full assistance, there remained a high probability of transfer to a convalescent rehabilitation ward if the patient was younger than 79.5 years and had three or more family members. Patients are expected to improve further when admitted to a convalescent rehabilitation ward [6]. Previous studies have also shown that a patient's age and the number of family members were related to home discharge [7-9]. Our data indicate that transfer to a convalescent rehabilitation ward may be more appropriate in this group, with the ultimate goal being home discharge. Moreover, patients with a total FIM score $>35$, a BRS of the lower $\operatorname{limb} \leq \mathrm{V}$, and an FIM motor score $\leq 44$ had approximately a $70 \%$ chance of discharge to a convalescent 
rehabilitation ward. Requiring moderate to maximal assistance in the total FIM at stroke onset, excluding items related to bathing and locomotion, may predict recovery in future rehabilitation.

Factors associated with discharge to other facilities, such as other hospitals or long-term care facilities, were near-total assistance on the ADL assessment, age 80 years or over, and the need for more than moderate assistance with expression. This suggests that not only motor function but also cognitive function must be severely impaired for patients to be discharged to other facilities. In clinical practice, even if there is severe dysfunction at onset, patients can recover function in the future, and patients with family support at home are often first transferred to a convalescent rehabilitation ward. Although severe disability makes home discharge difficult, there are cases in which it may remain possible, such as when there is adequate support from family and welfare services. The results of this study were consistent with those of previous studies [11].

Several studies have been done using regression analysis to predict discharge destinations after stroke $[7-11,13]$, but few have used CART analysis. For example, Falconer et al. used CART analysis to show that independence in toilet management, bladder management, and toilet transfer, as well as adequacy of financial resources, affected the outcomes of patients after stroke [27]. Furthermore, El-Solh et al. reported that several variables predicted the discharge destination of stroke patients in post-acute geriatric rehabilitation units. These were as follows: age; preadmission living environment; nursing severity index; cardiac, musculoskeletal-integument, and lower gastrointestinal symptoms; toileting transfer; and toilet management [32]. By using signal detection analysis, Miyamoto et al. also showed that ADLs, key person preference, age, gender, route taken to hospitalization, residence before hospitalization, and diagnosis of dementia were significant predictors of discharge destination [2]. Even though there are differences in the methods of analysis, the variables associated with discharge destination tend to be the same in these studies. However, because CART analysis can provide a model diagram (e.g., Fig. 1) of the complex interaction of factors relating discharge destination, it provides more useful information for clinical reasoning compared with logistic regression analysis. Furthermore, this study showed multiple clinical indicators in the acute phase of patients, who were expected long-term recovery and eventually would be discharged to their home by placing convalescent rehabilitation ward in the category of discharge destination.

We believe that the present study would provide useful information for occupational therapy practice in the acute phase of stroke. First, occupational therapists will be able to concretely examine the priority of patients' daily life problems in the acute phase with a long-term perspective, by using these clinical indicators to make discharge predictions. Second, occupational therapists will be able to more accurately conceptualize the occupational therapy goals under discharge prediction, taking into consideration the needs of patients and their families, and as a result, it would be possible to introduce interventions, not only viewpoints of physical and cognitive functions but also activities, occupations or environment adjustment in the acute phase. We believe that the goals of occupational therapy according to patients' future life are definitely reflected in the goals of the acute rehabilitation team. Third, occupational therapists will be able to communicate patients' problems, particularly with respect to the next stage after the acute phase; i.e., occupational therapists are required to coordinate service contents and support systems necessary for patients in post-discharge institution, and the results of this study are considered to be useful as appropriate discharge plan in acute stroke patients. American Occupational Therapy Association (AOTA) recommends that occupational therapy's holistic approach should focus on patient's goals and integrate occupation-based activities into the rehabilitation process of acute care [33]. Moreover, AOTA also recommends that occupational therapists collaborate closely with other health care professionals to create an interdisciplinary plan of care and a coordinated and appropriate discharge plan [33]. Therefore, the present study is believed to further promote occupational therapists' practices in the acute phase of stroke.

\section{Study Limitations}

This study has several limitations. First, we only included patients from one acute care ward, making it is difficult to generalize our findings and making multicenter collaboration necessary in the future. Second, previous studies have reported that it is desirable to consider a patient's discharge destination soon after symptom onset to screen for further interventions $[2,7]$. However, predicting discharge as a short-term outcome is not necessarily synonymous with predicting optimal rehabilitation and long-term outcomes [34]. Given that it has also been reported that outcomes should not be predicted before day seven after a stroke [35], there remains a need to confirm the optimal time at which outcomes should be predicted. Third, we did not include key background factors, such as household income, housing conditions, and local community resources, that are known to be important when making discharge decisions. Verification of the role of these is needed in 
future research, aiming to determine whether their inclusion produces different decision trees in CART analysis. Finally, with regard to statistical analysis, because there are many items to consider in this study, there are concerns about the problem of multiple testing. Thus, further verification is necessary in the future.

\section{Conclusion}

The findings of this study suggested that degree of independence on the FIM, function of the paralyzed lower limb, age, number of family members, and comprehension or expression function influence the choice of discharge destination for patients from acute stroke wards. However, further studies are needed to clarify the clinical indicators that determine the likely discharge destination from acute stroke wards. This is because intervention of occupational therapists based on accurate prognostic prediction in acute stroke rehabilitation is extremely important for supporting patients' activities and social participation.

\section{Conflicts of Interest}

The authors have no conflicts of interest to declare.

Acknowledgments: The authors would like to thank all the study patients.

\section{References}

[1] Summers D, Leonard A, Wentworth D, Saver JL, Simpson J, Spilker JA, et al. Comprehensive overview of nursing and interdisciplinary care of the acute ischemic stroke patient: a scientific statement from the American Heart Association. Stroke. 2009; 40(8): 2911-44.

[2] Miyamoto H, Hagihara A, and Nobutomo K. Predicting the discharge destination of rehabilitation patients using a signal detection approach. J Rehabil Med. 2008; 40(4): 261-8.

[3] Brauer SG, Bew PG, Kuys SS, Lynch MR, and Morrison G. Prediction of discharge destination after stroke using the motor assessment scale on admission: a prospective, multisite study. Arch Phys Med Rehabil. 2008; 89(6): 1061-5.

[4] Van der Cruyssen K, Vereeck L, Saeys W, and Remmen R. Prognostic factors for discharge destination after acute stroke: a comprehensive literature review. Disabil Rehabil. 2015; 37(14): 1214-27.

[5] Duncan PW, Zorowitz R, Bates B, Choi JY, Glasberg JJ, Graham GD, et al. Management of adult stroke rehabilitation care: a clinical practice guideline. Stroke. 2005; 36(9): e100-43.

[6] Abo M, and Kakuda W. Rehabilitation for cerebrovas- cular disease: current and new methods in Japan. Japan Med Assoc J. 2012; 55(3): 240-5.

[7] Bohannon RW, Lee N, and Maljanian R. Postadmission function best predicts acute hospital outcomes after stroke. Am J Phys Med Rehabil. 2002; 81(10): 726-30.

[8] Freburger JK, Holmes GM, Ku LJ, Cutchin MP, Heatwole-Shank K, and Edwards LJ. Disparities in postacute rehabilitation care for stroke: an analysis of the state inpatient databases. Arch Phys Med Rehabil. 2011; 92(8): 1220-9.

[9] Agarwal V, McRae MP, Bhardwaj A, and Teasell RW. A model to aid in the prediction of discharge location for stroke rehabilitation patients. Arch Phys Med Rehabil. 2003; 84(11): 1703-9.

[10] Roberts PS, Mix J, Rupp K, Younan C, Mui W, Riggs RV, et al. Using functional status in the acute hospital to predict discharge destination for stroke patients. Am J Phys Med Rehabil. 2016; 95(6): 416-24.

[11] Tanwir S, Montgomery K, Chari V, and Nesathurai S. Stroke rehabilitation: availability of a family member as caregiver and discharge destination. Eur J Phys Rehabil Med. 2014; 50(3): 355-62.

[12] Mees M, Klein J, Yperzeele L, Vanacker P, and Cras P. Predicting discharge destination after stroke: A systematic review. Clin Neurol Neurosurg. 2016; 142: 15-21.

[13] Dutrieux RD, van Eijk M, van Mierlo ML, van Heugten CM, Visser-Meily JM, and Achterberg WP. Discharge home after acute stroke: Differences between older and younger patients. J Rehabil Med. 2016; 48(1): 14-8.

[14] Tinl ML, Kale MK, Doshi S, Guarino AJ, and Beninato M. The mobility scale for acute stroke predicts discharge destination after acute hospitalization. J Rehabil Med. 2014; 46(3): 219-24.

[15] Maeshima S, Okamoto S, Okazaki H, Mizuno S, Asano N, Maeda $\mathrm{H}$, et al. Potential factors, including activities of daily living, influencing home discharge for patients with putaminal haemorrhage. BMC Neurol. 2016; 16: 16.

[16] Sone T, Nakaya N, Iokawa K, Hasegawa K, Tsukada T, Kaneda M, et al. Prediction of upper limb recovery in the acute phase of cerebrovascular disease: evaluation of "functional hand" using the manual function test. J Stroke Cerebrovasc Dis. 2015; 24(4): 815-22.

[17] Ohta T, Waga S, Handa W, Saito I, and Takeuchi K. New grading of level of disordered consiousness (in Japanese). No Shinkei Geka. 1974; 2(9): 623-7.

[18] Brunnstrom S. Movement therapy in hemiplegia: a neurophysiological approach. New York: Harper \& Row, 1970.

[19] Collin C, and Wade D. Assessing motor impairment after stroke: a pilot reliability study. J Neurol Neurosurg Psychiatry. 1990; 53(7): 576-9.

[20] Holden MK, Gill KM, Magliozzi MR, Nathan J, and Piehl-Baker L. Clinical gait assessment in the neurologically impaired. Reliability and meaningfulness. Phys Ther. 1984; 64(1): 35-40.

[21] Kato S, Shimogaki H, Onodera A, Ueda H, Oikawa K, Ikeda $\mathrm{K}$, et al. Development of the revised version of Hasegawa's Dementia Scale (HDS-R) (in Japanese). Jpn 
J Geriatr Psychiatry. 1991; 2: 1339-47.

[22] Granger CV, Hamilton BB, Keith RA, Zielezny M, and Sherwin FS. Advances in functional assessment for medical rehabilitation. Top Geriatr Rehabil. 1986; 1(3): 5974.

[23] Tanaka R, Umehara T, Fujimura T, and Ozawa J. Clinical prediction rule for declines in activities of daily living at 6 months after surgery for hip fracture repair. Arch Phys Med Rehabil. 2016; 97(12): 2076-84.

[24] Hung LC, Hu YH, and Sung SF. Exploring the impact of intravenous thrombolysis on length of stay for acute ischemic stroke: a retrospective cohort study. BMC Health Serv Res. 2015; 15: 404.

[25] Arai T, Kaneko S, and Fujita H. Decision trees on gait independence in patients with femoral neck fracture (in Japanese). Nihon Ronen Igakkai Zasshi. 2011; 48(5): 539-44.

[26] Bernhardt J, Churilov L, Ellery F, Collier J, Chamberlain $\mathrm{J}$, Langhorne P, et al. Prespecified dose-response analysis for A Very Early Rehabilitation Trial (AVERT). Neurology. 2016; 86(23): 2138-45.

[27] Falconer JA, Naughton BJ, Dunlop DD, Roth EJ, Strasser DC, and Sinacore JM. Predicting stroke inpatient rehabilitation outcome using a classification tree approach. Arch Phys Med Rehabil. 1994; 75(6): 619-25.

[28] de Haart M, Geurts AC, Huidekoper SC, Fasotti L, and van Limbeek J. Recovery of standing balance in postacute stroke patients: a rehabilitation cohort study. Arch Phys Med Rehabil. 2004; 85(6): 886-95.

[29] Granger CV, Hamilton BB, Linacre JM, Heinemann AW, and Wright BD. Performance profiles of the functional independence measure. Am J Phys Med Rehabil. 1993; 72(2): 84-9.

[30] Tsuji T, Sonoda S, and Chino N. The ADL structure for stroke patients at admission and dischage based on the functional independence measure (in Japanese). Jpm J Rehabil Med. 1996; 33(5): 301-9.

[31] Tsuji T, Sonoda S, Domen K, Saitoh E, Liu M, and Chino N. ADL structure for stroke patients in Japan based on the functional independence measure. Am J Phys Med Rehabil. 1995; 74(6): 432-8.

[32] El-Solh AA, Saltzman SK, Ramadan FH, and Naughton BJ. Validity of an artificial neural network in predicting discharge destination from a postacute geriatric rehabilitation unit. Arch Phys Med Rehabil. 2000; 81(10): 138893.

[33] The American Occupational Therapy Association, Inc [online]. Montgomery: Occupational Therapy in Acute Care [cited 2018 October 30]. Available from: https:// www.aota.org/About-Occupational-Therapy/Professionals/ RDP/AcuteCare.aspx

[34] Meijer R, van Limbeek J, Peusens G, Rulkens M, Dankoor K, Vermeulen M, et al. The Stroke Unit Discharge Guideline, a prognostic framework for the discharge outcome from the hospital stroke unit. A prospective cohort study. Clin Rehabil. 2005; 19(7): 770-8.

[35] Woldag H, Gerhold LL, de Groot M, Wohlfart K, Wagner A, and Hummelsheim H. Early prediction of functional outcome after stroke. Brain Inj. 2006; 20(10): 1047-52. 